\title{
An Experimental Study on the Effect of Tire Powder on the Geotechnical Properties of Clay Soils
}

\author{
Davood Akbarimehr ${ }^{\mathrm{a}}$, Esmael Aflaki ${ }^{\mathrm{b}^{*}}$ \\ ${ }^{a}$ PhD Student, Department of Civil and Environmental Engineering, Amirkabir University of Technology, Tehran,Iran. \\ ${ }^{b}$ Associated Professor, Department of Civil and Environmental Engineering, Amirkabir University of Technology, Tehran, Iran.
}

Received 12 January 2018; Accepted 08 March 2018

\begin{abstract}
With respect to the increasing production of tire wastes, the use of these wastes as an additive in civil engineering has always gained attentions of researchers due to their positive effects on material properties and reduction of environmental problems. Clay soils, as problematic soils, have always caused geotechnical problems including high Atterberg limits and consequently low workability. Tire powder, as one of the products of tire wastes, lacks clay cohesion and it can be effective in altering the plasticity of clay soils. As no comprehensive study has been conducted in this regard specifically on Tehran clay soil yet, this research studies experimentally the effect of adding different percentages of tire powder to clay soil at the Atterberg limits of clay soils with two different types of plasticity. More over according to previous studies, the effect of tire powder on other geotechnical properties of clay soils and the advantages and disadvantages of using tire powder in clay soils are discussed. The results indicate that addition of tire powder to clay soils has positive effects on reducing the Atterberg limits, increasing efficiency, and improving resistance, permeability, swelling reduction, and settlement properties, and reducing soil density and it can be used as an additive in improving clay soils.
\end{abstract}

Keywords: Tehran Clay; Waste Tire; Atterberg Limits; Geotechnical Properties.

\section{Introduction}

Urban life and its development have led to the production of abundant wastes. Production of wastes and consequently the environmental problems caused by their control and disposal are among the world issues. There are different methods to control the wastes including burying wastes in landfills, burning, separating, and reusing them. Some of the methods, including burial of wastes may lead to very adverse environmental impacts such as environmental pollution and occupation of the lands suitable for agricultural and industrial activities. One appropriate method to control wastes is their reuse in various industries; it reduces the volume of final waste and realizes sustainable development objectives. With the increasing development of urban and interurban transportation, waste tires are considered one of the waste, which have caused many problems, especially from an environmental point of view for human societies, and controlling the pollution caused by them is significant [1].

Soil improvement to improve the physical and mechanical properties of soil has always gained attentions. In these methods, soil properties are evaluated using necessary tests and field tests if necessary. If soil geotechnical properties fail to meet the requirements of a proper design, improvement methods will be applied in the next step to improve its properties. There are several methods for improving soil properties including the use of piles, chemical grouting, micro piles, physical and chemical methods, compaction, and dynamic compaction [2]. Selection of an improvement method depends on soil type and the required geotechnical properties of soil. Physical and chemical methods are of the best

* Corresponding author: eaflaki@aut.ac.ir

dol http://dx.doi.org/10.28991/cej-0309118

$>$ This is an open access article under the CC-BY license (https://creativecommons.org/licenses/by/4.0/).

(C) Authors retain all copyrights. 
improvement methods for clay soils. These methods improve soil geotechnical specifications by adding an additive. The use of chemical materials, cement, lime, and physical materials such as fibbers and various wastes have gained attentions of researchers for many years [2]. The use of wastes, especially tire wastes, can be considered as one of the physical and chemical improvement methods for soil. The use of waste tires has a very significant history in civil engineering. These wastes have been used in different ways including asphalt additives, concrete additives and as a sandy soil physical improver in different forms such as tire powder, crumb tire and tire chips. The use of tire wastes aimed at improving resistance, ductility, the use of excess wastes, environmental positive effects, and their lightness [3-16].

Despite conducting different and extensive studies on the geotechnical properties of the mixture of sandy soils and tire wastes, few studies have been carried out on clay soils and tire wastes. Reuse of the wastes in soil improves the geotechnical properties of poor and problematic clay soils and can have great advantages in environmental geotechnical field. With respect to the limited research on the effect of tire powder on the geotechnical properties of clay soils, the use of the wastes to improve clay soils will be remarkable and will provide environmental advantages. Tire wastes can be used in different projects for improvement and one of the major types of the projects would be road construction projects. Clay soils are of the soils found in nature and they are often problematic due to their properties [2]. One problem of clay soils in different projects includes their plasticity properties and high Atterberg limits. Due to the plasticity properties of clay soils, they have low workability and make executive operations difficult. On the other hand, tire powder is of the materials capable of being used as a physical additive in soil; as it lacks plasticity properties and it can change and improve the Atterberg limits of clay soils. Another prominent feature of the product made of tire wastes is its uniformity, which can exhibit a more homogeneous and repeatable behaviour for soil after mixing with natural soil. Meanwhile, no research has been conducted on the use of the wastes in Tehran clay soil, which can be considered as a new applied field in this concern. Therefore, attempts are made in this study to assess the effect of tire powder as an additive on the Atterberg limits of high- and low-plasticity clay soils and compare them based on the earlier experimental studies. As the evaluation of the Atterberg limits as well as other geotechnical properties of soil is important for engineering applications, some explanations have been provided with respect to the earlier studies in this field and the advantages and disadvantages of the use of tire powder in clay soil improvement have been evaluated.

The following section presented the research history and the earlier studies on the use of tire wastes and tire powders in civil and geotechnical engineering and research. At the Following section methods and consuming materials were explained individually. "Analysis of the Results and Discussion" section evaluated and analysed the results obtained from the laboratory tests separately. This section discussed and analysed the effect of tire powder on the geotechnical properties of clay soils and analysed and explained the advantages and disadvantages of the use of tire powder. "Conclusion" was presented in the final section.

\section{Literature review}

With regard to the increasing production of transportation network in the world and consequently the production of various industrial, agricultural, personal, public, and construction vehicles, the production of different wastes of the vehicles including their tires has created serious problems for human societies. One suitable solution to consume the wastes is to use them in construction activities and to improve different types of materials used in this field. The use of tire waste has been discussed over the past years in various parts of applied fields in civil engineering including waterproofing systems, asphalt, concrete, landfill liners [3-6]. The major reasons to use tire wastes in different industries include environmental issues, lightness, high damping, and appropriate resistance. Addition of different types of tire wastes including shred, chips, crumble, and fibber to soils has been observed in different resources to improve the geotechnical properties of sandy soils [7-16].

Few studies have been conducted on the addition of wastes to clay soil. Following studies were on the effect of tire powder and other tire wastes on the geotechnical properties of clay soils.

In 2012, Sarvade and Shet studied the effect of tire powder on the geotechnical properties of high-plasticity clay soil [17]. This research considered the evaluation of the Atterberg limits of soil through changing tire powder percentage. The results show that liquid limit is reduced by 6 percent with the increase of 5 percent of tire powder to the clay soil and plastic limit is reduced by 5.8 percent. These researchers also evaluate plastic limit and plasticity index and the results show an increase in plasticity index with the increase of tire powder percentage, which declines after reaching a peak. Meanwhile, the changes of plastic limit with the powder percentage increasing show a decreasing trend. The studies of researchers on the changes of maximum dry density and optimum water content showed that the changes of maximum dry density have always been declining with the increasing of tire powder to clay soil up to about 25 weight percentage of clay soil. However, the percentage changes of soil optimum water content were decreasing up to 10 percent increase of tire powder and it then had an increasing trend. In 2012, Trouzine et al. studied the effect of tire wastes on the Atterberg limits, swelling index, and coefficient of contraction of clay soils. This research showed that the liquid limit and swell potential of clay soils decreased and compression index and recompression index increased with the tire fiber increasing [18]. In 2013, Kalkan studied some geotechnical properties including permeability, compaction, resistance, and the swelling pressure of clay mix containing tire fibber [19]. The research results show that maximum dry density and optimum moisture content reduced with the tire percentage increasing and the use of 2 percent of tire fibber is an optimum content for improving soil resistance properties using a uniaxial compression test. In 2014, Tiwari 
et al. studied the properties of a clay soil-tire mixture and observed that maximum dry density and optimum moisture content increased with the crumb tire sizes reducing. The samples exhibit a more brittle behavior at the water content lower than optimum water content; however, they will show a more flexible behavior with the water content exceeding the optimum range [20]. In 2014, Prasad et al. studied the effect of adding crumb tire on compaction and uniaxial tests [21]. The research results indicate that maximum dry density and optimal water content reduce with the tire powder percentage increasing. The reduction can be justified in a way that the tire density is lower than soil density. The reduction of optimum humidity percentage can be due to the slight water absorption by tire powder. In 2015, Hambirao and Rakaraddi conducted some studies using various additives on reviewing problematic soil stabilization methods [22]. In 2016, Signes et al. examined the effect of adding tire powder to clay soil on the geotechnical properties of clay soil [23]. Research results showed that the increase of tire powder percentage reduces optimum water content and the maximum dry density of clay soil. Examination of the uniaxial resistance of the mixture samples showed no considerable change in the uniaxial resistance between the ones containing less than 5 percent of crumb tire and pure soil. In 2016, Tajdini et al. studied the resistance of clays containing crumb tire and concluded that the angle of internal friction of soil increases with the approximate increase of 10 percent of crumb tire [24]. In 2017, Mukherjee and Mishra examined soil resistance and observed that the effective adhesion of a sand-bentonite mixture is evident with a 10-percent increase of crumb tire [25]. The compression index of soil reduces with the approximate increase of tire chips by 10 percent.

\section{Methodology and Consuming Materials}

As the research mainly aimed at examining the effect of tire powder on the geotechnical properties of clay soils, natural soil materials and tire powder materials available in the market were used to make research results applicable and to make the results usable in practical projects. As per the technical specifications, the tire powder materials and clay soils used in the research are as follows:

\subsection{Clay Soil}

High- and low-plasticity clay soils were used in this research to meet different clay soils in the work plan. Natural clay soil was used to make the work applicable. Tehran clay soil was used for low-plasticity clay soil. Tehran clay soil was mixed with varied percentages of bentonite to prepare the soil suitable for high plasticity clay classification criteria; finally, 30 percent of bentonite was used, which meets the criteria for these type of soils. Table 1 and Figure 1 show the specifications for the Atterberg limits and the Casagrande chart of used soils, respectively. The figure shows that the used soils are in $\mathrm{CL}$ and $\mathrm{CH}$ Sections of the Casagrande chart and they are appropriate samples. Figure 2 shows the gradation curve of used clay soils. This figure show that the major part of soils is fine-grained and smaller than sieve No. 200. It should be noted that the soil passed through sieve No. 40 were used for these tests as per the instructions for the Atterberg tests.

Table 1. Atterberg limits of clay soils used in this study

\begin{tabular}{cc|cc}
\hline \multicolumn{2}{c|}{ High plasticity clay soil } & \multicolumn{2}{c}{ Low plasticity clay soil } \\
\hline Soil property & Water content (\%) & Soil property & Water content (\%) \\
\hline Liquid Limit & 75 & Liquid Limit & 33 \\
Plastic Limit & 28 & Plastic Limit & 17 \\
\hline Plasticity Index & 47 & Plasticity Index & 16 \\
\hline & & \\
\hline
\end{tabular}

Figure 1. Position of the $\mathrm{CL}$ and $\mathrm{CH}$ used clay soils in the Casagrande chart 


\subsection{Tire Powder}

The tire powder was purchased from the market. The powder consists of the tire passed through sieve No. 40. Figure 2 shows the gradation curve of tire powder. Figure 3 shows the image of used tire powder.

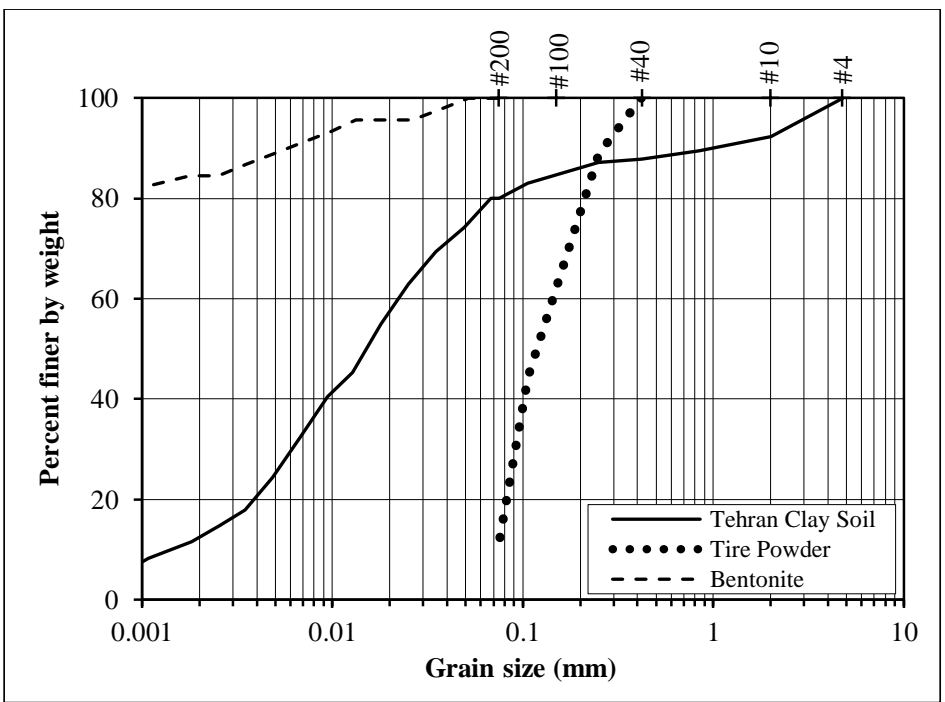

Figure 2. Gradation curve of clay and tire powder materials

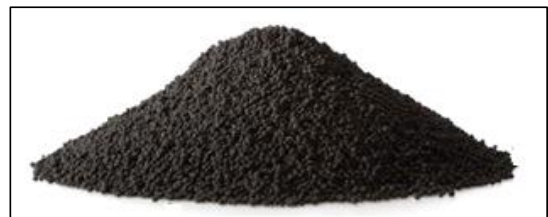

Figure 3. Tire powder

\subsection{Clay Soil-Tire Powder Mixture}

Different methods can be selected for mixing clay soil and tire powder including weight and volume methods. In this research, air-dried soil and tire powder with certain weight percentages were mixed to prepare an appropriate combination of tire powder and clay soil. Table 2 shows the weight composition of soil and tire powder.

The tests for the Atterberg limits, including the liquid limit and the plastic limit, are the conventional tests used in the tests for soil mechanics. The plasticity index can be calculated by liquid limit and plastic limit. The conventional methods were used as per ASTM D 4318 standard to perform the tests. As per the standard, an appropriate amount of soil was selected and it was placed in a suitable bag for about 24 hours after mixing with water to distribute moisture uniformly in the clay. A Casagrande apparatus was used to perform the liquid limit test and a conventional method was used for measuring the plastic limit as per the standard. The soils used in the test and the tire powder had been passed through sieve No. 40 as per the standard instruction.

The test schedule was organized in a way that $\mathrm{CL}$ and $\mathrm{CH}$ clay soils were prepared by combining a certain amount of tire powder and the liquid limit and plastic limit tests were performed on the samples. Plastic index can be calculated easily by these two parameters of the mixture.

Table 2. Weight composition of clay soils and tire powder

\begin{tabular}{|c|c|c|c|c|c|c|c|c|}
\hline \multirow{2}{*}{$\begin{array}{l}\text { Sampl } \\
\text { e No. }\end{array}$} & \multirow{2}{*}{ Soil type } & \multicolumn{7}{|c|}{ Tire Powder Percentage } \\
\hline & & 0 & 5 & 10 & 15 & 20 & 25 & 30 \\
\hline 1 & & 邓 & & & & & & \\
\hline 2 & & & ఐ & & & & & \\
\hline 3 & & & & ఐ & & & & \\
\hline 4 & CL & & & & $\bowtie$ & & & \\
\hline 5 & & & & & & $\bowtie$ & & \\
\hline 6 & & & & & & & $\otimes$ & \\
\hline 7 & & & & & & & & 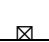 \\
\hline 8 & & 风 & & & & & & \\
\hline 9 & & & $\nabla$ & & & & & \\
\hline 10 & & & & $\nabla$ & & & & \\
\hline 11 & $\mathrm{CH}$ & & & & 风 & & & \\
\hline 12 & & & & & & 风 & & \\
\hline 13 & & & & & & & 风 & \\
\hline 14 & & & & & & & & 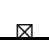 \\
\hline
\end{tabular}




\section{Analysis of Results and Discussion}

This section provides some explanations with respect to the method presented in the "Methodology" section on the effect of tire powder on the Atterberg limits of clay soils. The remaining section discusses the effect of tire powder on other geotechnical properties of clay soils and the disadvantages and advantages of the use of tire powder in improving clay soils.

Figure 4 shows the changes of the Atterberg limits of low-plasticity clay soil by adding tire powder. It shows that liquid limit reduces in this type of soil with the tire powder percentage increasing. Of course, the reduction is not highly significant. An approximate 10 percent increase of tire powder shows a reduction in liquid limit; however, liquid limit is almost fixed up to an approximate increase of 30 percent of tire powder. An increasing trend is observed for plastic limit with an approximate increase of 10 percent of tire powder. A slight slope is seen in the diagram with an increasing amount of tire powder. Plasticity index changes indicate a considerable reduction for plastic index with a 10 percent increase of tire powder. Afterwards, plasticity index changes will remain fixed with the tire powder increasing. Therefore, addition of an approximate amount of 10 percent of tire powder reduces liquid limit and plasticity index considerable. This should be noted that the best percentage of using tire powder in low plasticity clays-tire powder mixtures should be proposed with respect to the intended application in design and implementation and the results obtained from other test results.

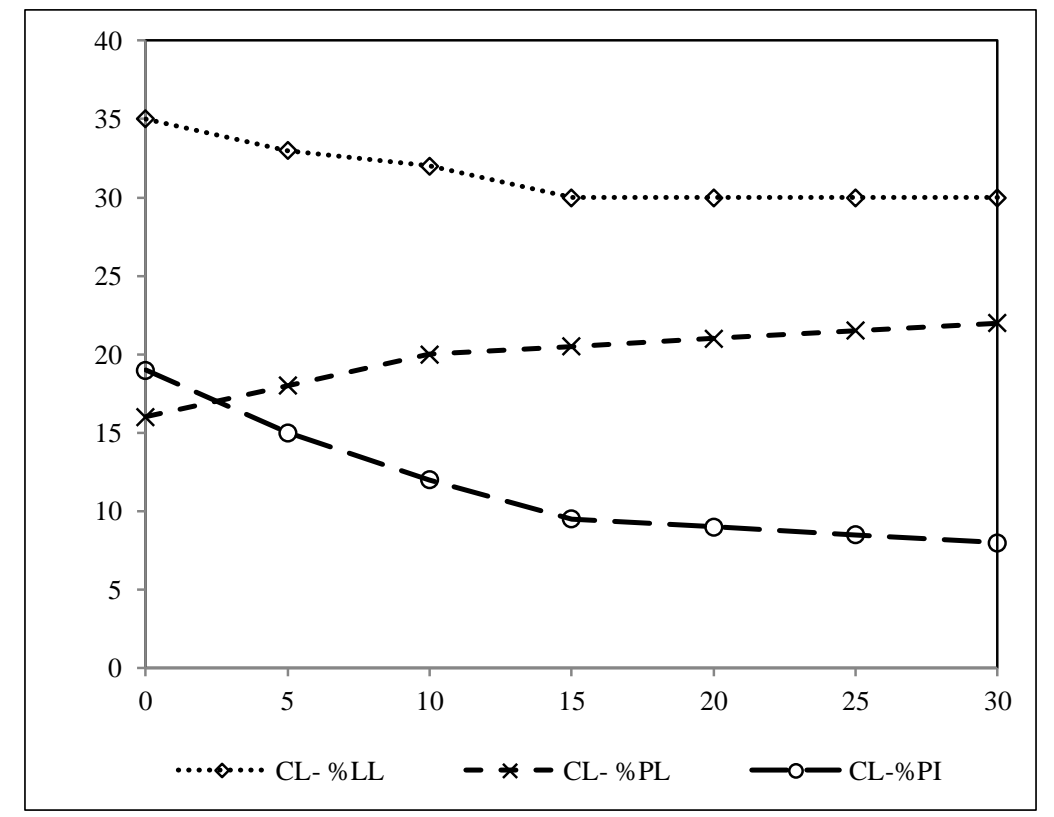

Figure 4. Variation of Atterberg limits of high-plasticity clay-tire powder mixtures

Figure 5 shows the changes of the Atterberg limits of high-plasticity clay soil by adding tire powder. It shows that the increase of tire powder percentage reduces liquid limit in soil. However, the reduction is considerable with an approximate increase of 30 percent of tire powder. A rising trend is seen on the plastic limit with an approximate increase of 10 percent of tire powder. Afterwards, a decreasing trend is observed in the diagram with the tire powder increasing up to 30 percent tire powder in the mixture. The plasticity index changes indicate that there is a decreasing trend in the plasticity index with an increase of tire powder by 10 percent. Afterwards, plasticity index reduction will be higher with the tire powder percentage increasing by 30 percent. Consequently, tire powder addition reduces the Atterberg limits of high-plasticity clay soils. As the considerable reduction of the Atterberg limits occurs at the high amounts of tire powder, the application, resistance, and other geotechnical properties of a mixture should be considered while using it. 


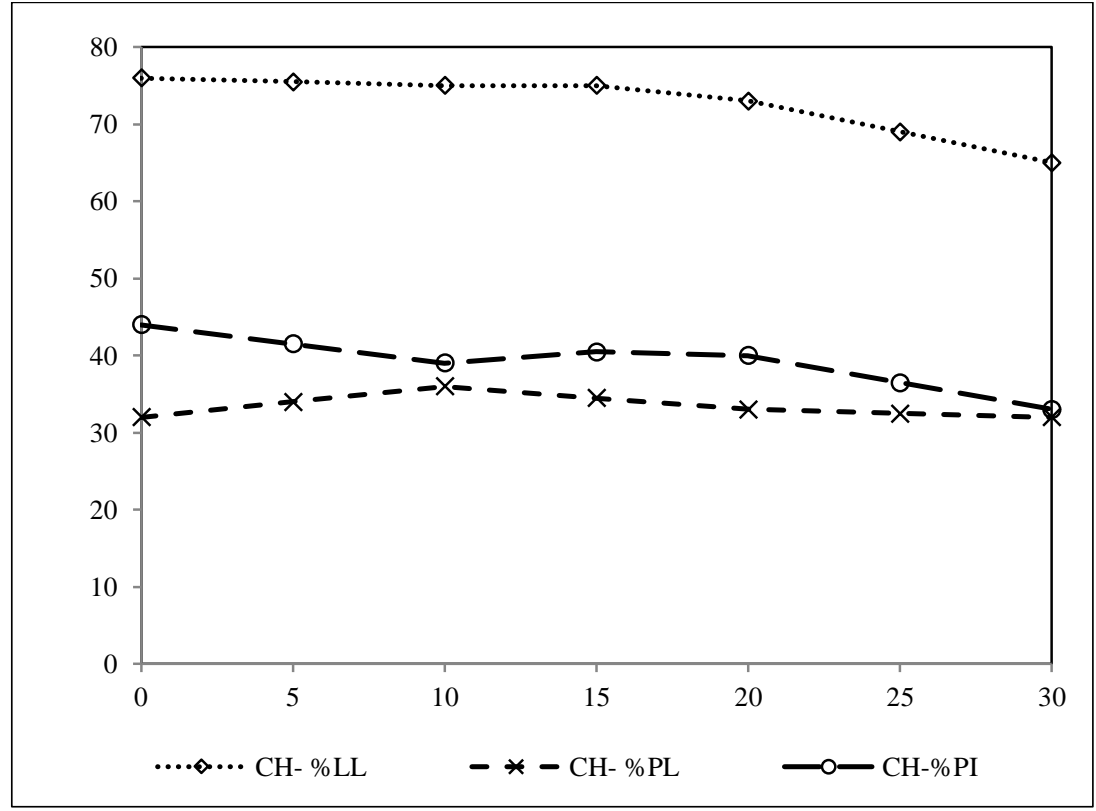

Figure 5. Variation of Atterberg limits of low-plasticity clay-tire powder mixtures

The comparison between the changes of the Atterberg limits in low-plasticity soils and the high-plasticity clay soils allows commenting about the soils, which are not equivalent to the two types of soils in terms of the specifications of the Atterberg limits but they are close to them in terms of classification. The liquid limit indicates that a decreasing trend is seen with the tire powder percentage increasing in both types of clay soils. An increasing trend is seen on the plastic limit of both types of clay soils with the increase of tire powder percentage and with about 10 percent increase of tire powder and plastic limit remains fixed by adding more tire powder percentage. The changes of plasticity index in both types of soils indicate that the plastic index has a decreasing trend. The changes and reduction of the Atterberg limit with the increase of tire powder percentage in low-plasticity clay soils at low percentages of tire powder are considerable, which should be considered in an engineering application.

Rubber powder is the finest product of rubber wastes. Its major advantages include improving clay soils efficiency and causing certain changes in their Atterberg limits. Crossing in a workshop, especially in the presence of water, is one of the problems of clay soils in projects. As the soils are highly cohesive, they cause a considerable amount of mud when accompanying with water, which reduces the quality of crossing, reduces crossing speed, and increases pollution in workshop area. The use of rubber powder improves such property and system efficiency, which has been proved in this research through research tests and reduction of the Atterberg limits. This is considered as one of the advantages of tire powder in engineering applications.

The changes caused by adding tire powder to clay soils and the changes caused in the compaction test, optimum humidity percentage, and maximum density, and with respect to research history, it can be concluded that addition of tire powder reduces maximum dry density and increases optimum water content in most cases. Maximum density reduces because the ratio of tire density to clay soil is low. Of course, it should be noted that density reduction does not necessarily mean resistance reduction and resistance tests are required for mixture quality evaluation. As water absorption by tire powder is limited, the increase of optimum moisture content can be predicted by the increase of tire powder percentage.

On the resistance changes caused by adding tire powder to clay soil, it can be considered based on the research history that the resistance of a clay soil-tire powder mixture at low percentages of tire powder in the uniaxial tests remains constant or increases up to the approximate resistance of 10 percent. However, the resistance reduces considerably at higher percentages. Normally, the resistance reduction percentage of high-plasticity soils exceeds the one of the lowplasticity clay soils. As the limits of favorable changes of the Atterberg limits for low-plasticity clay soils are about 10 percent, the possibility for an appropriate use of tire powder in low-plasticity clay soils exceeds the use of tire powder for soil improvement in high-plasticity soils when a favorable resistance in soil improvement is expected. Of course, it should be noted that the uniaxial test could be reliable at a low confining pressures. In this test, soil cohesion causes soil resistance and the changes of internal friction angle have no considerable effect on it. The use of more accurate tests, including triaxial tests and direct shear tests, provides further accurate information about the overall evaluation of clay soil-tire powder mixture resistance.

On the effect of different forms of tire wasted on soil permeability, it can be mentioned that mixture permeability increases with the size of tire wastes and their percentage increasing in a soil mixture. Tire powder is made of the finest components of tire; therefore, it is predicted that the use of tire dimensions has the minimum effect on the permeability 
of clay soils. For the uses of clay soils in which low-permeability of soil is important, the use of tire powder, as one of the appropriate additives, will be possible after studying the resistance of clay- tire powder mixtures. This way, the wastes are used and it has positive environmental effects.

As tire powder has no plastic property and its volume remains unchanged after adding water, it may have a significant role on controlling the swell of swelling high-plasticity clay soils. Conducting research in this field may be effective and applied for determining the relevant quantitative effects.

One of the characteristics of tire powder as compared with other wastes made of tire is that it has an appropriate homogeneity and may create repeatability features in soil, which is a significant issue in geotechnical engineering, and is one of the strengths of the use of other tire wastes.

One of the significant and effective issues of the use of tire powder in applied issues is its low density, which may be effective in reducing structure weight and saving structure in a project. A retaining wall and the use of tire powder with soil for its rear embankment may be of the important capabilities of tire powder. Of course, necessary studies should be conducted on resistance issues if necessary.

The advantages of using tire powder in the geotechnical properties of clay soils were mentioned above. One of the disadvantages of using tire wastes and tire powder in geotechnical engineering may be the sensitivity of determining the optimal amount of consumption. Of course, it should be noted that this issue has always been significant in using physical and chemical materials and it is required to determine the optimal consumption. This is important because the use of these materials without considering their optimal consumption may lead to the negative effects on geotechnical properties. The studies on the use of tire wastes, especially tire powder, prove that the use of tire powder at low percentages has a technical justification. This might be a disadvantage of using tire powder in engineering applications and the environmental importance of using tire powder in soil is far more than the positive effects in soil geotechnical properties. One problem caused by the consumption of tire wastes more than the optimal amounts in mixing with soil may be reduction of resistance by the excessive use of tire powder percentage. Therefore, it is necessary to determine an optimal amount in executive applications.

\section{Conclusion}

Research results show that the use of tire powder as a physical additive can improve the properties of Atterberg limits of high- and low-plasticity clay soils in engineering applications. A relatively similar and completely predictable process is seen in both types of clay soils with varied plasticities and the plasticity properties of clay soil and tire powder can be generalized in similar cases. The changes of liquid limit in both clay soils have an almost reducing process by increasing tire powder. An increasing trend is seen for the plastic limit up to 10 percent of tire powder in both clay soils and then an almost fixed and reducing process is observed. The changes of soil plasticity index with an approximate increase of 10 percent tire powder have been a reducing process and then some slight changes are seen in it. The severity of the Atterberg limits in high-plasticity clay soils exceeds the one of the low-plasticity clay soils.

The use of tire powder in geotechnical engineering has some advantages and disadvantages, which are as follows:

Making a significant change in the Atterberg limits of clay soils in various ranges of plastic properties, tire powder improves the efficiency of clay soil and improves engineering operations greatly. In terms of changing the geotechnical properties of clay soils, tire powder may affect resistance, permeability, settlement, and swelling and typically improve problematic soils. However, the accurate determination of the appropriate amount of powder depends on type of soil and the relevant properties for improvement. Most studies introduced low percentages of tire powder as the optimal percentage. In addition, the use of tire powder helps to solve the problems of tire wastes control and it is an acceptable measure environmentally. One of the disadvantages of using tire powder might be the accurate sensitivity of its optimal content under different conditions of engineering applications. Lack of accurate determination of powder percentage may have negative effects on geotechnical parameters, especially soil resistance that should be considered.

In case of using the research results in executive tasks, depending on the type of application, the test results to determine soil resistance and settlement should be evaluated accurately. This way, the properties of the Atterberg limits reduction in clay soils are used, the efficiency is improved, and some engineering preparations are made in executive tasks in terms of resistance and settlement if necessary.

\section{References}

[1] Thomas, Blessen Skariah, Ramesh Chandra Gupta, Pawan Kalla, and Laszlo Cseteneyi. "Strength, Abrasion and Permeation Characteristics of Cement Concrete Containing Discarded Rubber Fine Aggregates." Construction and Building Materials 59 (May 2014): 204-212. doi:10.1016/j.conbuildmat.2014.01.074.

[2] Kirsch, Klaus, and Alan Bell. “Ground Improvement, Third Edition” (November 28, 2012). doi:10.1201/b13678.

[3] Tortum, Ahmet, Cafer Çelik, and Abdulkadir Cüneyt Aydin. "Determination of the Optimum Conditions for Tire Rubber in 
Asphalt Concrete.” Building and Environment 40, no. 11 (November 2005): 1492-1504. doi:10.1016/j.buildenv.2004.11.013.

[4] Cao, Weidong. "Study on Properties of Recycled Tire Rubber Modified Asphalt Mixtures Using Dry Process." Construction and Building Materials 21, no. 5 (May 2007): 1011-1015. doi:10.1016/j.conbuildmat.2006.02.004.

[5] Pacheco-Torgal, F., Yining Ding, and Said Jalali. "Properties and Durability of Concrete Containing Polymeric Wastes (tyre Rubber and Polyethylene Terephthalate Bottles): An Overview." Construction and Building Materials 30 (May 2012): 714-724. doi:10.1016/j.conbuildmat.2011.11.047.

[6] Shu, Xiang, and Baoshan Huang. "Recycling of Waste Tire Rubber in Asphalt and Portland Cement Concrete: An Overview." Construction and Building Materials 67 (September 2014): 217-224. doi:10.1016/j.conbuildmat.2013.11.027.

[7] Pincus, HJ, TB Edil, and PJ Bosscher. "Engineering Properties of Tire Chips and Soil Mixtures." Geotechnical Testing Journal 17, no. 4 (1994): 453. doi:10.1520/gtj10306j.

[8] Zornberg, Jorge G, Alexandre R Cabral, and Chardphoom Viratjandr. "Behaviour of Tire Shred Sand Mixtures." Canadian Geotechnical Journal 41, no. 2 (April 2004): 227-241. doi:10.1139/t03-086.

[9] Ahmed, Imtiaz, and C. W. Lovell. "Rubber soils as lightweight geomaterials." Transportation research record 1422 (1993).

[10] Tatlisoz, Nilay, Tuncer B. Edil, and Craig H. Benson. "Interaction Between Reinforcing Geosynthetics and Soil-Tire Chip Mixtures." Journal of Geotechnical and Geoenvironmental Engineering 124, no. 11 (November 1998): 1109-1119. doi:10.1061/(asce)1090-0241(1998)124:11(1109).

[11] Rao, G. Venkatappa, and R. K. Dutta. "Compressibility and Strength Behaviour of Sand-tyre Chip Mixtures.” Geotechnical and Geological Engineering 24, no. 3 (June 2006): 711-724. doi:10.1007/s10706-004-4006-x.

[12] Attom, Mousa F. "The Use of Shredded Waste Tires to Improve the Geotechnical Engineering Properties of Sands." Environmental Geology 49, no. 4 (December 23, 2005): 497-503. doi:10.1007/s00254-005-0003-5.

[13] Foose, Gary J., Craig H. Benson, and Peter J. Bosscher. "Sand Reinforced with Shredded Waste Tires.” Journal of Geotechnical Engineering 122, no. 9 (September 1996): 760-767. doi:10.1061/(asce)0733-9410(1996)122:9(760).

[14] Moo-Young, Horace, Kassahun Sellasie, Daniel Zeroka, and Gajanan Sabnis. "Physical and Chemical Properties of Recycled Tire Shreds for Use in Construction.” Journal of Environmental Engineering 129, no. 10 (October 2003): 921-929. doi:10.1061/(asce)0733-9372(2003)129:10(921).

[15] Cabalar, A. F., and Z. Karabash. "California Bearing Ratio of a Sub-Base Material Modified With Tire Buffings and Cement Addition.” Journal of Testing and Evaluation 43, no. 6 (October 10, 2014): 20130070. doi:10.1520/jte20130070.

[16] Neaz Sheikh, M., M. S. Mashiri, J. S. Vinod, and Hing-Ho Tsang. "Shear and Compressibility Behavior of Sand-Tire Crumb Mixtures." Journal of Materials in Civil Engineering 25, no. 10 (October 2013): 1366-1374. doi:10.1061/(asce)mt.19435533.0000696.

[17] Sarvade, Purushotham G. "Geotechnical Properties of Problem Clay Stabilized with Crumb Rubber Powder." Bonfring International Journal of Industrial Engineering and Management Science 2, no. 4 (December 28, 2012): 27-32. doi:10.9756/bijiems.1671.

[18] Trouzine, H., M. Bekhiti, and A. Asroun. "Effects of Scrap Tyre Rubber Fibre on Swelling Behaviour of Two Clayey Soils in Algeria." Geosynthetics International 19, no. 2 (April 2012): 124-132. doi:10.1680/gein.2012.19.2.124.

[19] Kalkan, Ekrem. "Preparation of Scrap Tire Rubber Fiber-silica Fume Mixtures for Modification of Clayey Soils." Applied Clay Science 80-81 (August 2013): 117-125. doi:10.1016/j.clay.2013.06.014.

[20] Tiwari, Binod, Beena Ajmera, Suzanne Moubayed, Alexander Lemmon, Kelby Styler, and Josh Guerrero Martinez. "Improving Geotechnical Behavior of Clayey Soils with Shredded Rubber Tires-Preliminary Study." Geo-Congress 2014 Technical Papers (February 24, 2014). doi:10.1061/9780784413272.362.

[21] Prasad, A. Shiva, P. T. Ravichandran, R. Annadurai, and P. R. Rajkumar. "Study on effect of crumb rubber on behavior of soil." International Journal of Geomatics and Geosciences 4, no. 3 (2014): 579-584.

[22] Hambirao, Ghatge Sandeep, and Dr.P.G. Rakaraddi. "Soil Stabilization Using Waste Shredded Rubber Tyre Chips." IOSR Journal of Mechanical and Civil Engineering 11, no. 1 (2014): 20-27. doi:10.9790/1684-11152027.

[23] Hidalgo Signes, Carlos, Julio Garzón-Roca, Pablo Martínez Fernández, Maria Elvira Garrido de la Torre, and Ricardo Insa Franco. "Swelling Potential Reduction of Spanish Argillaceous Marlstone Facies Tap Soil through the Addition of Crumb Rubber Particles from Scrap Tyres.” Applied Clay Science 132-133 (November 2016): 768-773. doi:10.1016/j.clay.2016.07.027.

[24] Tajdini, Milad, Ali Nabizadeh, Hasan Taherkhani, and Hosein Zartaj. "Effect of Added Waste Rubber on the Properties and Failure Mode of Kaolinite Clay." International Journal of Civil Engineering 15, no. 6 (July 29, 2016): 949-958. doi:10.1007/s40999016-0057-7.

[25] Mukherjee, K., and A. K. Mishra. "The Impact of Scrapped Tyre Chips on the Mechanical Properties of Liner Materials." Environmental Processes 4, no. 1 (January 24, 2017): 219-233. doi:10.1007/s40710-017-0210-6. 